\title{
Therapeutic Effect of Varenicline on Depression Among Cigarette Smokers with Methadone Maintenance Therapy
}

\author{
Mohammad Talebpoor ${ }^{1}$, Ghasem dastgerdii ${ }^{1 *}$, Reza Bidaki ${ }^{1,2}$ and Mahmood Vakili ${ }^{3}$ \\ ${ }^{1}$ Research Center of Addiction and Behavioral Sciences, Shahid Sadoughi University of Medical Sciences, Iran \\ ${ }^{2}$ Diabetes Research Center, Shahid Sadoughi University of Medical Sciences, Iran
}

${ }^{3}$ Community and Preventive Medicine Department, Shahid Sadoughi University of Medical Sciences, Iran

*Corresponding author: Ghasem dastgerdi, Research Center of Addiction and Behavioral Sciences, Shahid Sadoughi University of Medical Sciences, Yazd, Iran.

\begin{abstract}
Introduction: Varenicline is an effective drug approved for smoking cessation. This study was conducted to evaluate the effect of Varenicline on depression in smokers treated with methadone.

Methods: The present study was a double-blind randomized clinical trial that was performed on 60 smokers aged 18-60 years old who were referred to addiction treatment clinics who had a primary diagnosis of major depression based on the DSM-5 criteria. Both groups were treated with Citalopram tablets $20 \mathrm{mg}$ daily for the treatment of depression. For the group of varenicline for 6 weeks, the first three days $0.5 \mathrm{mg}$, followed by $1 \mathrm{mg}$ daily and the control group was given the same placebo. Both groups were evaluated using BDI-II by a psychiatrist before the intervention, 3 and 6 weeks after treatment.

Results: The mean and standard deviation of the depression scores in the Varenicline group and the control after intervention were $19.74 \pm 6.36$ and $21.39 \pm 6.4$ respectively, and the estimated effect size was 0.259 , that according to the Cohen table was lower than the mean. There was no significant difference between the mean depressions scores in the Varenicline group before intervention 29.85 and in the control group were 30.32. At 3 and 6 weeks after treatment, the depression score in the Varenicline group was lower than that of the other drug effects; however, this difference was not statistically significant.
\end{abstract}

Conclusion: Varenicline is a relatively effective drug for smokers with depression who are treated with methadone.

Keywords: Depression; Methadone; Varenicline; Nicotine; Smoking cessation

\section{Introduction}

Major depressive disorder is a common, chronic, and severe disease and community-related research has shown that between $3-11 \%$ of the world's population suffers from these disorders every year. It is expected that this disorder will be the second-largest disorder in the world by 2020 [1]. Depression is a serious and prevalent affective disorder that surpassed only the consumption of substances and phobias. According to the World Health Organization, around 121 million people worldwide suffer from this disorder, and this disorder is one of the major disabling factors around the world. The risk of life-long depression for women is estimated at $10-25 \%$ and for men $5-12 \%$. Forecasts suggest that, by 2020 , depression will be the second cause of global health damage
[2]. Many patients with depression have failed to receive adequate treatment and many patients despite appropriate treatment, up to one-third did not improve. Pre-clinical studies show the antidepressive effects of drugs that target nicotine acetylcholine receptors, which observe the most consistent results with the regulators of alpha 4 beta 2 nicotinic receptors such as varenicline and non-specific antagonists such as Mecamylamine. The regulators of nicotine acetylcholine receptors affect neurological processes, including the behavioral effects of antidepressants, such as cell proliferation in the hippocampus. Clinical and pre-clinical evidence suggests that drugs that target nicotinic acetylcholine receptors may be an important approach to treating depression [3]. 
Varenicline is an effective drug for the nicotinic acetylcholine receptor, which is an alpha 4 beta 2 partial agonist, and a complete alpha-7 agonist approved for smoking cessation. In tests, varenicline decreases the symptoms of nicotine withdrawal, including depression, anxiety, irritability, and sleep disorder [4, 5]. Varenicline in smoking cessation is effective and safe in treating patients with methadone [6]. Several pharmacological properties of varenicline are consistent with potentially potent antidepressants. Varenicline is a structure associated with plant alkaloid, which antidepressant effects have been found in animal models [7]. Through the activity of alpha 4 beta 2 nicotinic receptors in the nucleus accumbens, varenicline was able to modulate the neurotransmitter of dopamine [8, 9] and anhedonia caused by depression [10, 11]. According to other evidence, the Nicotine cholinergic system is involved in moderating mood in depression $[12,13]$. These findings have suggested that varenicline has an independent anti-depressant effect. But evaluations of such effects are not systematically carried out. Therefore, with regard to the above, this study was conducted as a randomized clinical trial with the aim of evaluating the effect of varenicline on major depressive disorder in smokers undergoing methadone treatment.

\section{Methods}

The present study was a randomized, double-blind clinical trial with the aim of determining the therapeutic effect of varenicline on the major depressive disorder in smokers undergoing methadone treatment. In this study, 60 smokers aged 18-60 who referred to Yazd addiction treatment clinics, primarily diagnosed with depression based on DSM-5 criteria, were randomly divided into two groups of varenicline and placebo. After a preliminary assessment and ensuring that the criteria for entry into the study were approved by the psychiatric assistant, both groups were treated with $20 \mathrm{mg}$ citalopram daily for a period of 6 weeks. On the first three days $0.5 \mathrm{mg}$ Varenicline was administrated (Kosar Pharmaceutical Company), followed by $1 \mathrm{mg}$ of Varenicline daily. The control group was given the same placebo. By fellow pharmacists, varenicline and placebo (starch) were prepared in similar capsule form, divided into two groups (A and B) by a pharmacist. Therefore, the psychiatrist resident, statistics consultant, and patients were not informed about drugs until the end of the study. Data were collected using the Beck Depression Inventory-II (BDI-II). It consists of 21 multiple choice questions ranging from 0-3, taking 5-10 minutes to complete. Wahhab and Parto confirmed the diagnostic value of the questionnaire in Iran in 1973 and 1974. Both groups were evaluated by the Beck Depression Inventory (BDI-II) by assistant psychiatrists in the third and sixth weeks. Of course, evaluation of depression score before the start of treatment was also performed for both groups. At the end of the sixth week, the drug complications questionnaire was completed by the patient. SPSS software version 21 was used to analyze data by appropriate statistical methods including chi-square, t-test, and paired t-test). The significance level was set at 0.05 .

\section{Results}

At first 60 patients were enrolled in the study, 5 of whom were excluded from the study due to discontinuation of the drug. The results of this study showed that the mean age of patients in the varenicline group was $37.33 \pm 8.52$ years and in the control group was 38.18 \pm 8.1 years. Also, in the group of varenicline, 26 (96.3\%) were male and 1 female (3.7\%) and all controls were male. There were no significant differences between the two groups regarding age and sex $(\mathrm{p}<0.05)$, and the two groups were similar in age and sex (Table 1). The mean number of years of smoking in the varenicline group was 18.22 and in the control group was 17.93, and this case was not significantly different between the two groups $(\mathrm{p}=0.91)$. In the Varenicline group, 21 (77.8\%) were married and $6(22.2 \%)$ were single while $21(75 \%)$ were married, 6 (1.21\%) were single and $1(3.6 \%)$ was divorced in the control group. The marital status did not differ between the two groups $(\mathrm{p}=0.61)$. There is also no significant difference in the level of education between groups.

Table 1: Patient's characteristics: comparison of the control and varenicline group.

\begin{tabular}{|c|c|c|c|}
\hline & $\begin{array}{c}\text { Control group } \\
\text { Total (n=28) }\end{array}$ & $\begin{array}{c}\text { Varenicline Group } \\
\text { Total (n=27) }\end{array}$ & P-value \\
\hline Age (years), Mean \pm SD & $38.18 \pm 8.1$ & $37.33 \pm 8.52$ & $>0.05$ \\
\hline Men & $28(100 \%)$ & $26(96.3 \%)$ & $>0.05$ \\
\hline Women & $0(0 \%)$ & $1(3.7 \%)$ & \\
\hline
\end{tabular}

The most common complication in the varenicline group was nausea $(44.4 \%)$ and dry mouth $(33.3 \%)$, and in the control group was nausea (25\%) and dry mouth $(21.4 \%)$. There was no significant difference between the groups in terms of complications $(p>0.05)$. The mean and standard deviation of the depression scores in the varenicline group and the control after intervention were $19.74 \pm 6.36$ and $21.39 \pm 6.4$ respectively, and the estimated effect size was 0.259 , the effect size according to the Cohen table was lower than the mean. The mean score of depression before the intervention was 29.85 and in the control group, it was 30.32 with no significant difference. At 3 and 6 weeks after treatment, although the depression score in the varenicline group was lower than the control group and the effect of the drug was better than the control group, this difference was not statistically significant (Table $2)$. The mean of depression scores in the varenicline group was 29.85 before the intervention, 23.67 after 3 weeks and 19.74 after 6 weeks. The difference was significant in the varenicline group using the paired t-test $(\mathrm{p}=0.001)$, and the depression scores of patients were significant with Varenicline treatment was reduced. In the control group, the difference was significant before the intervention and after 3 and 6 weeks, probably due to the treatment of all patients with citalopram, but the decrease in depression scores in the varenicline group was higher. 
Table 2: The mean Beck Depression test score between the two groups.

\begin{tabular}{|c|c|c|c|}
\hline Time & $\begin{array}{c}\text { Control group } \\
\text { Total }(\mathbf{n = 2 8})\end{array}$ & $\begin{array}{c}\text { Varenicline Group } \\
\text { Total (n=27) }\end{array}$ & P-value \\
\hline Before intervention & $30.32 \pm 5.8$ & $29.8 \pm 6.06$ & 0.77 \\
\hline 3 weeks after intervention & $24.25 \pm 5.5$ & $23.67 \pm 5.8$ & 0.69 \\
\hline 6 weeks after intervention & $21.39 \pm 6.4$ & $19.74 \pm 6.3$ & 0.34 \\
\hline
\end{tabular}

\section{Discussion}

Varenicline is an effective drug for the nicotinic acetylcholine receptor, which is an alpha 4 beta 2 partial agonist, and a full alpha-7 agonist approved for smoking cessation. In tests, Varenicline decreases the symptoms of nicotine withdrawal, including depression, anxiety, irritability, and sleep disorder $[9,13]$. Therefore, the present study was a double-blind randomized clinical trial with a therapeutic approach aimed at determining the therapeutic effect of Varenicline on the major depressive disorder in smokers treated with methadone. The results of this study showed that the mean depression scores in the varenicline group before intervention, 3 weeks later and 6 weeks later, despite the fact that depression score in the Varenicline group was lower than the control group and the effect of the drug was better than the control group, but this difference was not significant. But in each group, the mean depression score was significantly reduced during 3 weeks and 6 weeks after treatment, which was probably due to the effect of citalopram administration in all patients, but the decrease in the varenicline group was more than that in the control group. Also, there was no significant difference in side effects between the two groups in the evaluation of possible side effects. The most common complication in both groups was nausea and dry mouth.

The study of Philip et al. was conducted to investigate the effect of anti-depressant varenicline on depressed nicotine-dependent patients in 18 patients. In addition to routine treatment, patients were treated with Varenicline. Varenicline was initially started with a dose of $0.5 \mathrm{mg}$ daily and then titrated to $1 \mathrm{mg}$ twice a day for one week and lasted for up to 8 weeks if patients were tolerated. Four patients were excluded from the study due to adverse events, including gastrointestinal disorders, and worsening mood and irritability. Patients showed a significant improvement in the final outcome of depression. $44 \%$ of the patients responded to complete treatment and $33 \%$ were in the recovery phase, which was categorized according to the Depression Detection Questionnaire (QIDS-SR). Their study showed that symptom improvement has been observed since the second week of the follow-up. One of the differences between the present study and the Philip study was the sample size, the way depression was assessed in patients, the duration of the follow-up, and the lack of control group in their study [14]. Unlike the present study, the most common side effects in their study were sleep disorders. $44 \%$ of patients reported insomnia. While in previous studies, approximately $19 \%$ of patients had insomnia and this probably reflects an interaction between psychotropic drugs and varenicline, which requires extensive studies.
In another study by Patterson et al., prescribing Varenicline in smokers in a double-blind clinical trial, the Varenicline group showed lower negative affective symptoms compared with the control group which is in line with the side effects such as dry mouth, nausea and sleep disorder we found in the patients in this study. However, in their study, dry mouth, nausea, constipation, and sleep disorders were significantly higher in the varenicline group [15]. The findings of Avery et al. (2013) on 152 menopausal women showed that patients treated with varenicline had a lower CESD score (depression scale at the Center for Epidemiological Studies), which ultimately resulted in the effects of varenicline antidepressants, patient selection, use of relaxation or unknown cause [16]. Kausch's study showed that the administration of varenicline can improve depression and discontinue it in a smoker can cause recurrence of depressive periods. Their case study was from a 47-year-old man with chronic depression who was treated with varenicline because of cessation of smoking and significantly improved his symptoms [17]. In the study conducted by Antennule et al. on 525 adult smokers diagnosed with depression to evaluate the effect of varenicline on smoking cessation. There was no significant difference between the two groups in terms of thought or suicidal behavior, worsening of depression and anxiety. According to the present study, the most common side effect was nausea [18]. The results of this study and other studies, together with the evidence for the relative anti-depressant effect of the $\alpha 4 \beta 2$ partial agonist [8], and the evidence of the potential benefits of nicotinic receptor antagonist for major depression [19], suggest that varenicline may be effective as a treatment for mood disorders. According to this study, varenicline can be considered as a relatively effective drug for smokers treated with methadone with depression. According to the survey, this study was the first clinical trial to investigate the effect of varenicline on the treatment of depression in Iran. Considering its positive effect and decreasing depression score in patients, wider studies with larger sample sizes in both groups of smokers and non-smokers are recommended for a better understanding of the potential for anti-depressant effects of varenicline.

\section{Acknowledgment}

This paper was extracted from the dissertation of a psychiatry student having fulfilled his M.D psychiatrist degree in Yazd Medical University. The authors would like to thank the authorities and personnel of Yazd addiction clinics as well as the patients participating in the research.

\section{Disclosure Statement}

The authors declare no conflict of interest in this study. 


\section{Funding}

No funding was received.

\section{References}

1. Rouf K (2004) Oxford guide to behavioural experiments in cognitive therapy: OUP Oxford, UK.

2. Smith K, De Torres I (2014) A world of depression. Nature 515.

3. Philip NS, Carpenter LL, Tyrka AR, Price LH (2010) Nicotinic acetylcholine receptors and depression: a review of the preclinical and clinical literature. Psychopharmacology 212(1): 1-12.

4. Gonzales D, Rennard SI, Nides M, Oncken C, Azoulay S, et al. (2006) Varenicline, an $\alpha 4 \beta 2$ nicotinic acetylcholine receptor partial agonist, vs sustained-release bupropion and placebo for smoking cessation: a randomized controlled trial. Jama 296(1): 47-55.

5. Jorenby DE, Hays JT, Rigotti NA, Azoulay S, Watsky EJ, et al. (2006) Efficacy of varenicline, an $\alpha 4 \beta 2$ nicotinic acetylcholine receptor partial agonist, vs placebo or sustained-release bupropion for smoking cessation: a randomized controlled trial. Jama 296(1): 56-63.

6. Nahvi S, Ning Y, Segal KS, Richter KP, Arnsten JH (2014) Varenicline efficacy and safety among methadone maintained smokers: a randomized placebo-controlled trial. Addiction 109(9): 1554-1563.

7. Mineur YS, Somenzi O, Picciotto MR (2007) Cytisine, a partial agonist of high-affinity nicotinic acetylcholine receptors, has antidepressant-like properties in male C57BL/6J mice. Neuropharmacology 52(5): 12561262.

8. Mihalak KB, Carroll FI, Luetje CW (2006) Varenicline is a partial agonist at $\alpha 4 \beta 2$ and a full agonist at $\alpha 7$ neuronal nicotinic receptors. Molecular pharmacology 70(3): 801-805.

9. Rollema H, Chambers L, Coe J, Glowa J, Hurst R, et al. (2007) Pharmacological profile of the $\alpha 4 \beta 2$ nicotinic acetylcholine receptor partial agonist varenicline, an effective smoking cessation aid. Neuropharmacology 52(3):985-94.
10. Stahl SM (2003) Symptoms and circuits, part 1: major depressive disorder. J Clin Psychiatry 64(11): 1282-1283.

11. Dunlop BW, Nemeroff CB (2007) The role of dopamine in the pathophysiology of depression. Archives of general psychiatry 64(3): 327-337.

12. Shytle R, Silver A, Lukas R, Newman M, Sheehan D, et al. (2002) Nicotinic acetylcholine receptors as targets for antidepressants. Molecular psychiatry 7(6): 525-535.

13. Shytle RD, Silver AA, Sheehan KH, Sheehan DV, Sanberg PR (2002) Neuronal nicotinic receptor inhibition for treating mood disorders preliminary controlled evidence with mecamylamine. Depression and anxiety 16(3): 89-92.

14. Philip NS, Carpenter LL, Tyrka AR, Whiteley L, Price LH (2009) Varenicline augmentation in depressed smokers: an 8-week, open-label study. J Clin Psychiatry 70(7): 1020-1026.

15. Patterson F, Jepson C, Strasser AA, Loughead J, Perkins KA, et al. (2009) Varenicline improves mood and cognition during smoking abstinence. Biol psychiatry 65(2): 144-149.

16. Avery N, Kenny AM, Kleppinger A, Brindisi J, Litt MD, et al. (2014) Effects of varenicline, nicotine or placebo on depressive symptoms in postmenopausal smokers. The American journal on addictions 23(5): 459-465.

17. Kausch O (2014) Treatment of Depression in a Former Smoker With Varenicline? A Case Report and Discussion. The Journal of neuropsychiatry and clinical neurosciences 26(2): 172-175.

18. Anthenelli RM, Morris C, Ramey TS, Dubrava SJ, Tsilkos K, et al. (2013) Effects of varenicline on smoking cessation in adults with stably treated current or past major depression: a randomized trial. Ann Intern Med 159(6): 390-400.

19. George TP, Sacco KA, Vessicchio JC, Weinberger AH, Shytle RD (2008) Nicotinic antagonist augmentation of selective serotonin reuptake inhibitor-refractory major depressive disorder: a preliminary study. J Clin Psychopharmacol 28(3):340-344.

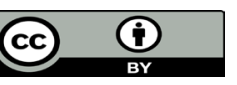

This work is licensed under Creative Commons Attribution 4.0 License

To Submit Your Article Click Here: Submit Article

DOI: $10.32474 /$ SJPBS.2020.03.000171

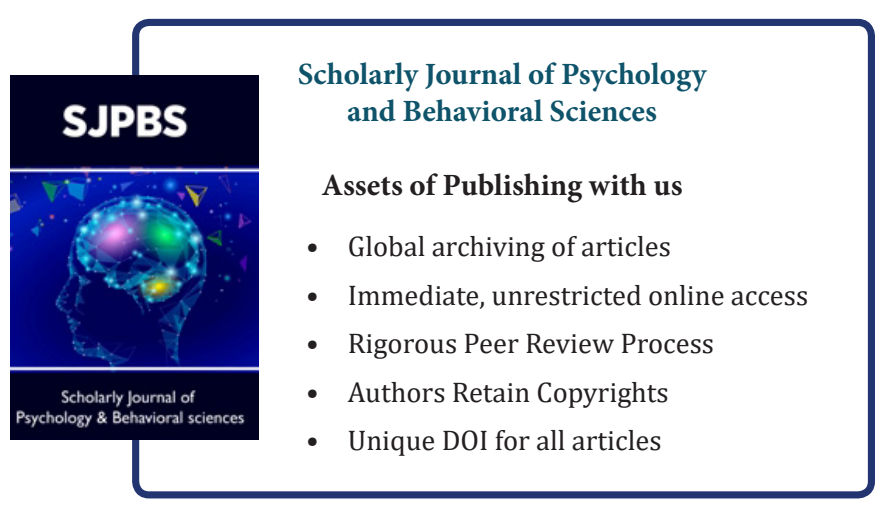

